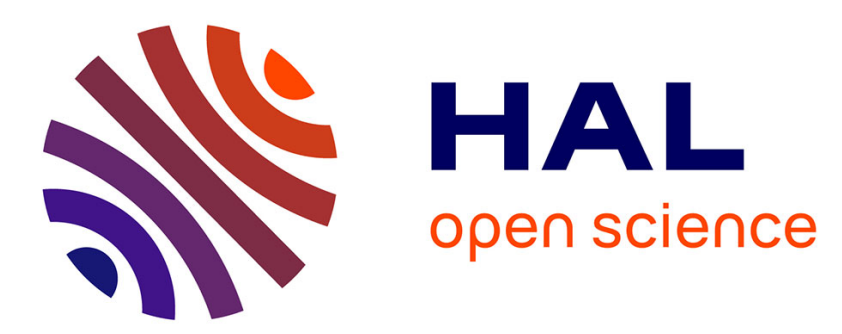

\title{
Effects of getters on hermetically sealed micromachined cesium-neon cells for atomic clocks
}

\author{
M. Hasegawa, R.K. Chutani, R. Boudot, L. Mauri, C. Gorecki, X. Liu, N.
}

Passilly

\section{- To cite this version:}

M. Hasegawa, R.K. Chutani, R. Boudot, L. Mauri, C. Gorecki, et al.. Effects of getters on hermetically sealed micromachined cesium-neon cells for atomic clocks. Journal of Micromechanics and Microengineering, 2013, 23, pp.055022. 10.1088/0960-1317/23/5/055022 . hal-00816649

\section{HAL Id: hal-00816649 \\ https://hal.science/hal-00816649}

Submitted on 18 Apr 2021

HAL is a multi-disciplinary open access archive for the deposit and dissemination of scientific research documents, whether they are published or not. The documents may come from teaching and research institutions in France or abroad, or from public or private research centers.
L'archive ouverte pluridisciplinaire HAL, est destinée au dépôt et à la diffusion de documents scientifiques de niveau recherche, publiés ou non, émanant des établissements d'enseignement et de recherche français ou étrangers, des laboratoires publics ou privés. 


\title{
Effects of getters on hermetically sealed micromachined cesium-neon cells for atomic clocks
}

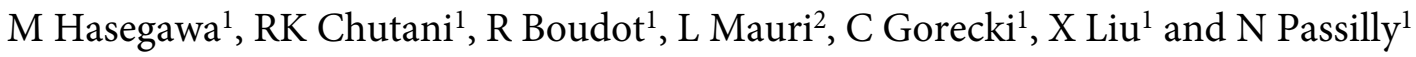 \\ ${ }^{1}$ FEMTO-ST Institute (CNRS UMR 6174/UFC/ENSMM/UTBM), 16, Route de Gray, F-25030 \\ Besançon, France \\ ${ }^{2}$ SAES Getters, Viale Italia 77, I-20020 Lainate, Milan, Italy \\ E-mail: nicolas.passilly@femto-st.fr
}

\begin{abstract}
The wafer-level integration technique of PageWafer ${ }^{\square \mathrm{R}}$ (SAES Getters' solution for getter film integration into wafer to wafer bonded devices) has been tested in hermetically sealed miniature glass-Si-glass cells filled with $\mathrm{Cs}$ and $\mathrm{Ne}$, e.g. for microelectromechanical systems (MEMS) atomic clock applications. Getter effects on the cell atmosphere are analyzed by quadruple mass spectroscopy and coherent population trapping (CPT) spectroscopy. The quadruple mass spectroscopy revealed that the residual gases $\left(\mathrm{H}_{2}, \mathrm{O}_{2}, \mathrm{~N}_{2}\right.$ and $\left.\mathrm{CO}_{2}\right)$ that are attributed to anodic bonding process are drastically reduced by the getter films while desirable gases such as $\mathrm{Ne}$ seem to remain unaffected. The impurity pressure in the getter-integrated cells was measured to be less than $4 \times 10^{-2} \mathrm{mbar}$, i.e. pressure 50 times lower than the one measured in the cells without getter (2 mbar). Consequently, the atmosphere of the getter-integrated cells is much more pure than that of the getter-free cells. CPT signals obtained from the getter-integrated cells are stable and are, in addition, similar to each other within a cell batch, suggesting the strong potential of applications of this getter film and especially for its wafer-level integration to MEMS atomic clocks and magnetometers.
\end{abstract}

\section{Introduction}

Hermetical sealing of microelectromechanical systems (MEMS) structures is one of the important fabrication steps in order to generate miniature devices such as alkali-vapor cells-based MEMS atomic sensors, i.e.atomic clocks [1], spectrometers [2] or magnetometers [3]. These devices require MEMS cells which contain a precisely controlled atmosphere that stays stable for short and long-term use. In this framework, the anodic bonding is one of the most reliable sealing techniques among many sealing technologies to achieve such MEMS devices. Although different alkali atoms ( $\mathrm{Rb}, \mathrm{Cs}$ ) as well as different techniques to fill the cavities with such atoms have been employed, most of them rely on anodic bonding in order to seal the cavities [1-9]. However, it has been shown that the devices sealed by anodic bonding contain considerable amount of residual gases such as $\mathrm{H}_{2}, \mathrm{O}_{2}, \mathrm{~N}_{2}$ and $\mathrm{CO}_{2}$ due to the bonding reaction and outgassing of glass substrate during high temperature processing [10]. Those gases might modify the inner cell atmosphere, especially for long-term use of the devices. Getter materials used to ensure vacuum in small cavities [11] can be an effective solution to solve the outgas problem. For instance, Ti coatings employed in the vacuum cavity of a gyroscope has been reported to minimize such impurity gases [12]. In this paper, we report the integration of PageWafer ${ }^{\circledR}$ to $\mathrm{Cs}-\mathrm{Ne}$ cells for micro atomic clock applications, which have been developed within the European project 'MEMS atomic clocks for timing, frequency control and communications (MAC-TFC)'. In the related micro atomic clock, the coherent population trapping (CPT) resonance is obtained in a microcell containing $\mathrm{Cs}$ and a single buffer gas, i.e. $\mathrm{Ne}$ [13]. For this purpose, the $\mathrm{Cs}-\mathrm{Ne}$ cell is illuminated by 


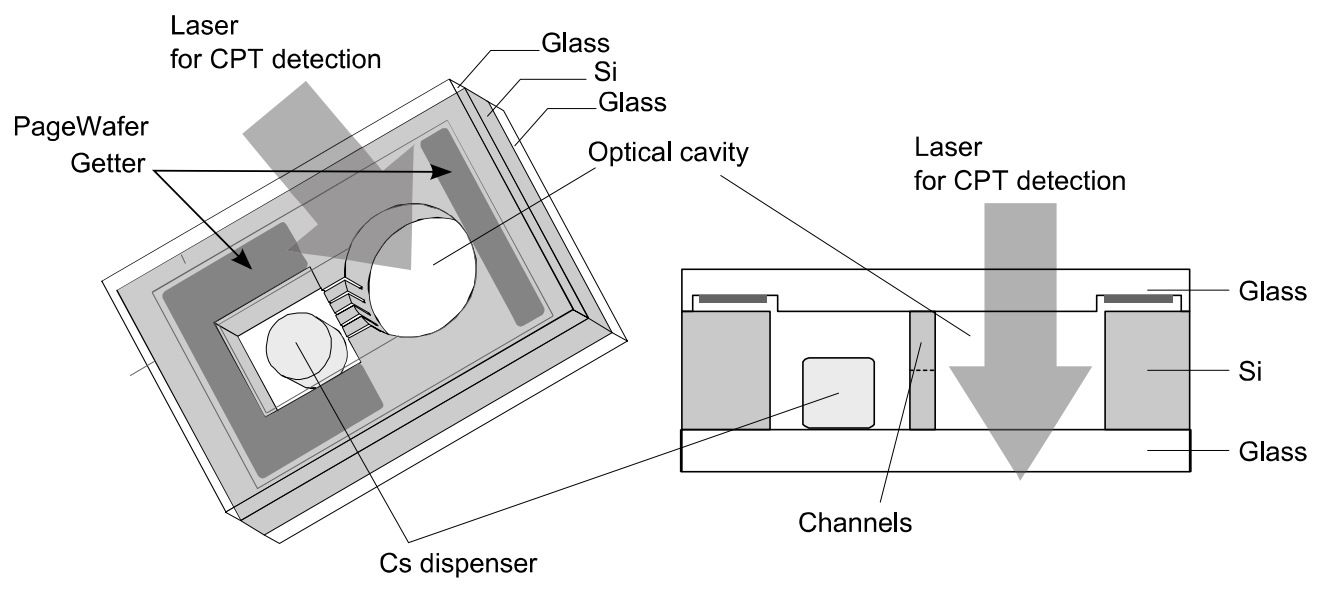

Figure 1. Schematic of the Cs-vapor cell.

a high-frequency modulated laser beam, which is subsequently collected by a photodiode delivering a signal in order to lock the frequency of a local oscillator on the well-defined atomic resonance $(9.192631770 \mathrm{GHz})$. We have reported previously successful fabrication of micro Cs-Ne cells based on a Cs filling method using a Cs dispenser, specifically developed by SAES Getters [14], combined with a two-step anodic bonding technique which allows the sealing of a required amount of buffer gas in the cells [15]. A CPT atomic clock using such a $\mathrm{Cs}-\mathrm{Ne}$ microcell achieved a short-term frequency stability of $1.5 \times 10^{-10} \tau^{-1 / 2}$ until 30s [16] and more recently $3.8 \times 10^{-11} \tau^{-1 / 2}$ until $1000 \mathrm{~s}$ [17] using a laser resonant with the Cs D1 line. In these experiments, a possible explanation of the clock frequency shift occurring after 1000s integration time is the variation of the cell atmosphere that could be related to reactions between very reactive alkali atoms such as Cs and impurities. Thus, for the practical stand point, the integration of PageWafer ${ }^{\circledR}$ to eliminate impurity gases seems to be interesting in order to further improve the reliability of Cs-cells, i.e. to get more pure atmosphere in the first place and avoid further undesirable reactions. We therefore studied the wafer-level integration of PageWafer ${ }^{\circledR}$ getter films for the Cs-Ne cells, and its sorption ability was investigated by using quadruple mass spectroscopy. The getter-integrated Cs-Ne cells were further examined through CPT spectroscopy.

\section{Micro Cs-vapor cells}

The Cs-vapor cells are made of a Si wafer sandwiched between two borosilicate glass wafers (figure 1). The cell structure is essentially the same as the one reported in [15]. The cell contains two cavities connected through micro surface channels: one for CPT resonance detection and the other for Cs dispenser storage, achieving an inner volume of nearly $7.5 \mathrm{~mm}^{3}$. In the case of cells having getters, the PageWafer ${ }^{\circledR}$ is deposited inside the cavity, in top-glass trenches located around the optical window and the dispenser cavity window, as shown in figure 1, before the sealing of the cavity. Fabrication process is outlined in figure 2. First, an array of cell cavities and the filtration channels are patterned and etched in a $\mathrm{Si}$ wafer by using deep reactive ion etching (DRIE), followed by an additional $\mathrm{KOH}$ surface treatment for surface quality improvement. In parallel, a $10 \mu \mathrm{m}$ deep cavity for getter deposition is etched in high frequency (HF) in a glass wafer, so-called cap wafer. For this purpose, a mask made of a layer of $\mathrm{Au} / \mathrm{Cr}$ is sputtered on both surfaces of the glass wafer for HF etching. The cavity patterns are transferred into the mask layer by photolithography, and the sample is immersed in an HF aqueous solution. Thus, PageWafer ${ }^{\circledR}$ is deposited inside the $10 \mu \mathrm{m}$ deep cavities.

Cell-sealing process essentially follows the process reported previously [15]. First, the getter-deposited top-glass wafer is anodically bonded to the Si wafer in vacuum. Once a Cs dispenser pill is placed in the cavity, the cell is sealed by anodic bonding in the chamber filled with Ne. For this step, we applied a two-step anodic bonding process in order to fill the cell cavity with $\mathrm{Ne}$ without the problem of electrical breakdown between electrodes when a high voltage is applied. After the sealing of the wafer, the array of microcells is diced into single cell chips. Finally, Cs dispenser pill is locally heated with a high-power laser source, so that the Cs vapor generated from the dispenser diffuses through the microchannels to the CPT detection cavity.

Since this activation for Cs vapor releasing is performed only after the cell sealing, the most efficient gettering is done in a Ne atmosphere. PageWafer ${ }^{\circledR}$ film sorption capacity for the various active gases is much higher under warm conditions, as it is during the bonding step, than at room temperature (almost two orders of magnitude at $450{ }^{\circ} \mathrm{C}$ ). This is because higher temperatures promote the diffusion of the chemisorbed gases from the surface of the getter film into its bulk. This higher capacity allows the PageWafer ${ }^{\circledR}$ film to also act as a 'process getter' allowing the sorption of a larger quantity of gases desorbed during the high-temperature bonding process. Besides, use of $\mathrm{Ne}$ as a buffer gas prevents the undesired effect of pressure decrease inside the microcell because noble gases are not absorbed by the getter film. Therefore, with this cell configuration, the CPT resonance frequency is not expected to vary because of cell atmosphere variations.

It can be noted that the top-glass wafer with deposited getters should be preferably bonded at last, i.e. in order to seal the cavity. Therefore, the getter would not undergo an activation during the first bonding process, as it is our 

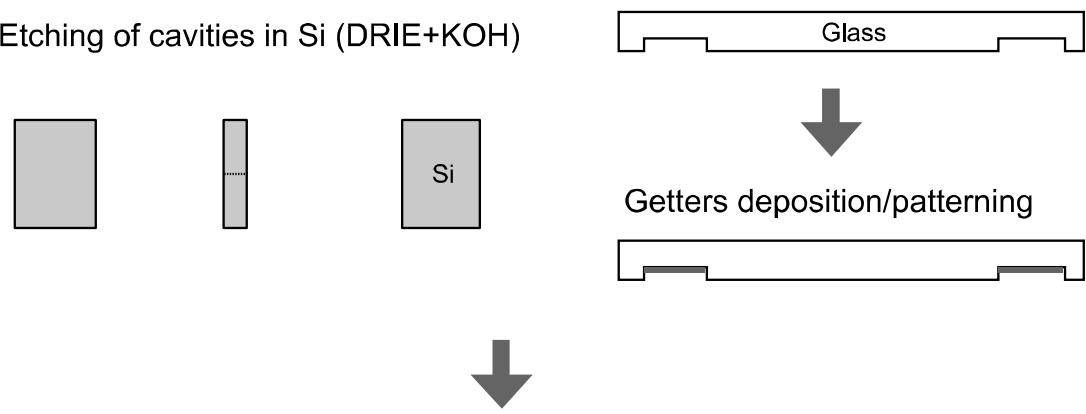

Anodic bonding of Si and glass
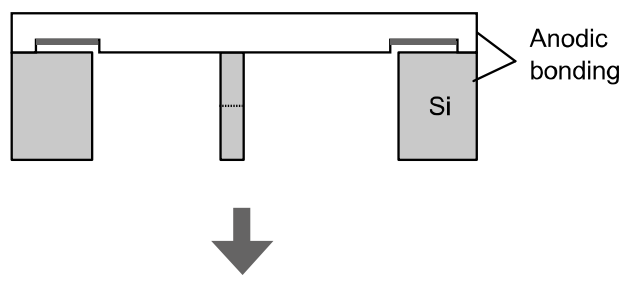

Filling of cells with buffer gas $(\mathrm{Ne})$

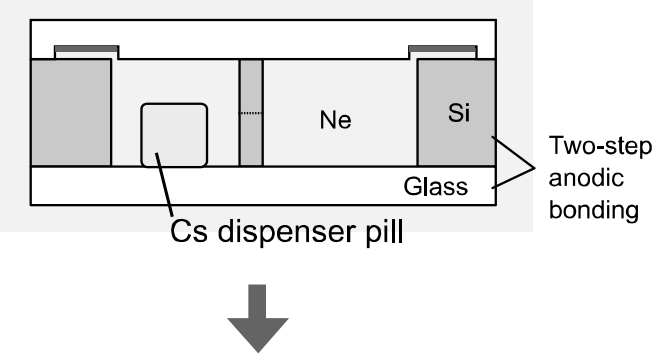

Cs dispensing by laser activation

Laser

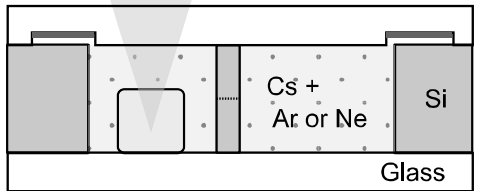

Figure 2. Fabrication steps of the micro Cs-vapor cell.

case (figure 2) due to alignment restrictions in the employed bonding machine. Despite the probably limited absorption performances of the getter with this flowchart, the following analyses demonstrate its efficiency, and thus its strong potential for purification of alkali vapor cell atmosphere.

\section{Residual gas analysis (RGA)}

The inner atmosphere of the cells has been analyzed at room temperature in an ultrahigh vacuum chamber equipped with a high sensitivity quadrupole mass spectrometer (QMS). The microcells used for this analysis (with QMS) contain Ne but neither a Cs dispenser nor Cs vapors in order to avoid possible partial gettering of $\mathrm{Cs}$ and also to simplify the residual gas analysis. Such a micro Ne-cell was placed in a small vacuum chamber equipped with an opening tool and a capacitance manometer. The chamber was evacuated and was isolated from the pumping system. Afterward, the cell was broken by an opening tool and the total pressure of the chamber was measured. The original pressure inside the cell is calculated by using the chamber and inner-cell volumes. After measurement of the total pressure, a small part of the gas was introduced to another chamber and its composition was investigated with QMS.

Table 1 compares the representative results of RGA obtained from a getter-free cell and a getter-integrated cell. The main impurities found in the getter-free cell (cell A) are $\mathrm{H}_{2}, \mathrm{~N}_{2}, \mathrm{O}_{2}$ and $\mathrm{CO}_{2}$, which are known to be generated during anodic bonding reaction and to be active gases [10, 18]. These gases were not detected in the getter-integrated cell (cell B), indicating that the PageWafer ${ }^{\circledR}$ efficiently absorbed these gases. The pressure of $\mathrm{Ne}$ in both cells is comparable; thus $\mathrm{Ne}$ is not absorbed by the PageWafer ${ }^{\circledR}$. The values are within the pressure error resulting from the precision of our $\mathrm{Ne}$ filling technique. In contrast to the above-mentioned gas species, it has to be mentioned that traces of hydrocarbons were detected (although four orders of magnitude lower than $\mathrm{Ne}$ pressure), which could be related to residual impurities 


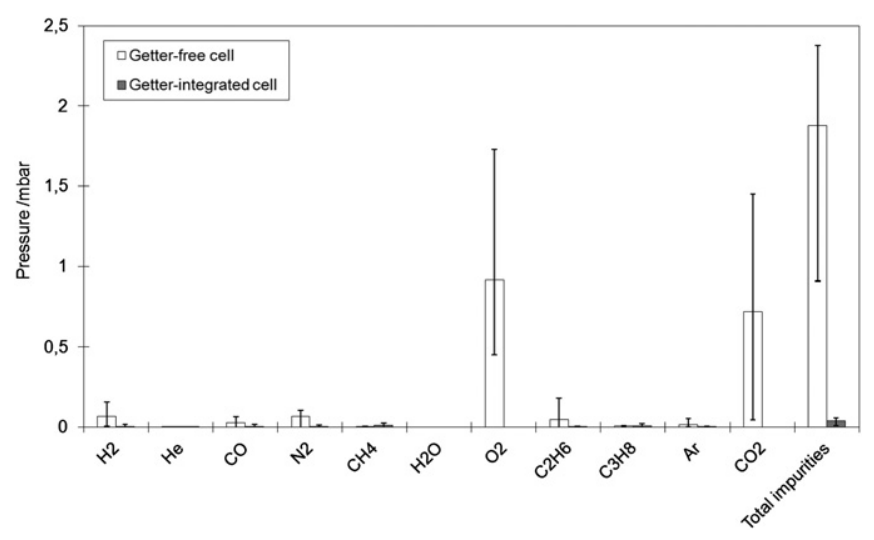

Figure 3. Residual gas pressure in Ne cells.

Table 1. Effects of getter films on cell atmosphere ${ }^{\mathrm{a}}$.

\begin{tabular}{lll}
\hline & \multicolumn{2}{c}{ Residual gas pressure (mbar) } \\
\cline { 2 - 3 } & Cell A (Getter-free) & Cell B (Getter-integrated) \\
\hline $\mathrm{H}_{2}$ & $2.76 \times 10^{-2}$ & 0.00 \\
$\mathrm{He}$ & $3.71 \times 10^{-3}$ & $1.63 \times 10^{-3}$ \\
$\mathrm{CO}$ & 0.00 & 0.00 \\
$\mathrm{~N}_{2}$ & $8.12 \times 10^{-2}$ & 0.00 \\
$\mathrm{CH}_{4}$ & $4.45 \times 10^{-3}$ & $2.79 \times 10^{-2}$ \\
$\mathrm{H}_{2} \mathrm{O}$ & 0.00 & 0.00 \\
$\mathrm{Ne}$ & $1.40 \times 10^{2}$ & $1.42 \times 10^{2}$ \\
$\mathrm{O}_{2}$ & $8.09 \times 10^{-1}$ & 0.00 \\
$\mathrm{C}_{2} \mathrm{H}_{6}$ & 0.00 & $5.28 \times 10^{-3}$ \\
$\mathrm{C}_{3} \mathrm{H}_{8}$ & $7.62 \times 10^{-3}$ & $2.12 \times 10^{-2}$ \\
$\mathrm{Ar}$ & $7.28 \times 10^{-3}$ & 0.00 \\
$\mathrm{CO}_{2}$ & 1.33 & 0.00 \\
\hline
\end{tabular}

${ }^{\mathrm{a}}$ Cells were filled with $\mathrm{Ne}$ (set pressure: 133 mbar).

of the manufacturing processes for getter patterning. Further optimization of the process will be required to improve the quality of the cell and further optimization of getter activation procedure during anodic bonding process will be investigated.

Figure 3 summarizes the averages of residual gas pressure corresponding to each impurity in the getter-free and getterintegrated cells. Four samples of the getter-free cells and six samples of the getter-integrated cells were randomly chosen for gas analysis. All cells are filled with $\mathrm{Ne}$ but contain neither Cs vapor nor a $\mathrm{Cs}$ dispenser. The total residual gas pressure is significantly reduced in the getter-integrated cells by comparison with the getter-free cells. It is also important to note that the pressure errors among the cells are drastically reduced for the getter-integrated cells. The average pressure of total impurities was $4 \times 10^{-2}$ mbar for the getter-integrated cells, whereas it was 2 mbar for the getter-free cells. In other terms, the residual gas remaining in the getter-integrated cells is $2 \%$ of that in the getter-free cells.

\section{CPT spectroscopy}

In addition, $\mathrm{Cs}-\mathrm{Ne}$ cells were characterized by $\mathrm{CPT}$ spectroscopy employing a laboratory-prototype Cs CPT-clock setup similar to the one described in [19] where a distributedfeedback diode laser emits light resonant frequency stabilized on the $\mathrm{Cs}_{\mathrm{D}_{1}}$ line at $\lambda=894.6 \mathrm{~nm}$. Thus, an electro-optic modulator (EOM), driven by a microwave local oscillator, is used to generate optical sidebands frequency-separated by $9.192 \mathrm{GHz}$ required for CPT interaction. The microwave source is driven by an ultra-stable reference hydrogen maser.

CPT spectroscopy is employed in here for Ne pressure estimation. Indeed, presence of Ne buffer gas, in addition to narrowing of CPT resonance thanks to Dicke effect [20], is also responsible for a shift of the Cs hyperfine resonance frequency [21]. Because this shift is proportional to $\mathrm{Ne}$ pressure, pressure uniformity among the fabricated cells and process reproducibility can be estimated. Experimentally, the measured clock frequency $f_{\text {clk }}$ results from four main contributions:

$$
f_{\mathrm{clk}}=f_{0}+a B^{2}+b I+\Delta f_{\mathrm{bg}}
$$

where $f_{0}$ is the frequency of the unperturbed Cs atom $(9.192631770 \mathrm{GHz}), a B^{2}$ is the quadratic Zeeman shift due to the static magnetic field $B\left(a=427 \mathrm{~Hz} / \mathrm{G}^{2}\right)$, $b I$ is the so-called light shift (frequency shift of the clock attributed to variations of the laser intensity $I$ ) and $\Delta f_{\text {bg }}$ is the collisional frequency shift due to the presence of buffer gas. Our objective is consequently to determine experimentally the value of $\Delta f_{\mathrm{bg}}$ in order to estimate the Ne pressure in the cell. For this purpose, the microcell temperature is fixed in the $60-80{ }^{\circ} \mathrm{C}$ range. The static magnetic field is $132 \mathrm{mG}$, inducing a fixed Zeeman shift of $7.4 \mathrm{~Hz}$. Then, the clock frequency is measured for various laser intensities in order to determine the linear light shift function $b I$. Finally, once the Zeeman shift taken into account, the collisional frequency shift $\Delta f_{\text {bg }}$ due to the presence of buffer gas is measured by extrapolation at zero intensity of the light shift curve. For $\mathrm{Ne}$, the collisional frequency shift $\Delta f_{\mathrm{bg}}$ is [22]:

$$
\begin{aligned}
\Delta f_{\mathrm{bg}}=P_{0} & \times\left(515.8+0.200 \times\left(T-T_{0}\right)+(-0.00126)\right. \\
& \left.\times\left(T-T_{0}\right)^{2}\right)
\end{aligned}
$$

where $P_{0}$ is the buffer gas pressure in mbar at the reference temperature of $T_{0}=0{ }^{\circ} \mathrm{C}$ and $T$ is the cell temperature $\left({ }^{\circ} \mathrm{C}\right)$. From equation (2), sensitivity of the clock frequency to buffer gas pressure is about $523.7 \mathrm{~Hz} / \mathrm{mbar}$ for cell temperatures from 60 to $80{ }^{\circ} \mathrm{C}$. In our experiment, the uncertainty on clock resonance frequency measurements was estimated to be $\pm 50 \mathrm{~Hz}$, limited by the fact that no electronics were available to lock the local oscillator frequency onto the atomic resonance. This uncertainty limits the estimation of Ne pressure value in the cell at a level of \pm 0.13 mbar.

\subsection{Batch pressure uniformity}

In a first step, Cs-Ne getter-cells were characterized from two different batches, called batch $\mathrm{A}$ and batch $\mathrm{B}$, resulting from two fabrication runs. Cells are then noted Axx and Bxx. Eight or more samples from each batch were examined using CPT spectroscopy. For each batch, the Ne set pressure during fabrication is $133 \mathrm{mbar}$ at $65{ }^{\circ} \mathrm{C}$. Figure 4 shows a typical CPT resonance detected in a cell (A04). The resonance is well fitted by a lorentzian function with a full-width at half maximum (FWHM) of $1.88 \mathrm{kHz}$. Measured FWHM of cells from batch $\mathrm{A}$ are in the range $[1.66 \mathrm{kHz}-1.96 \mathrm{kHz}]$ (average: 


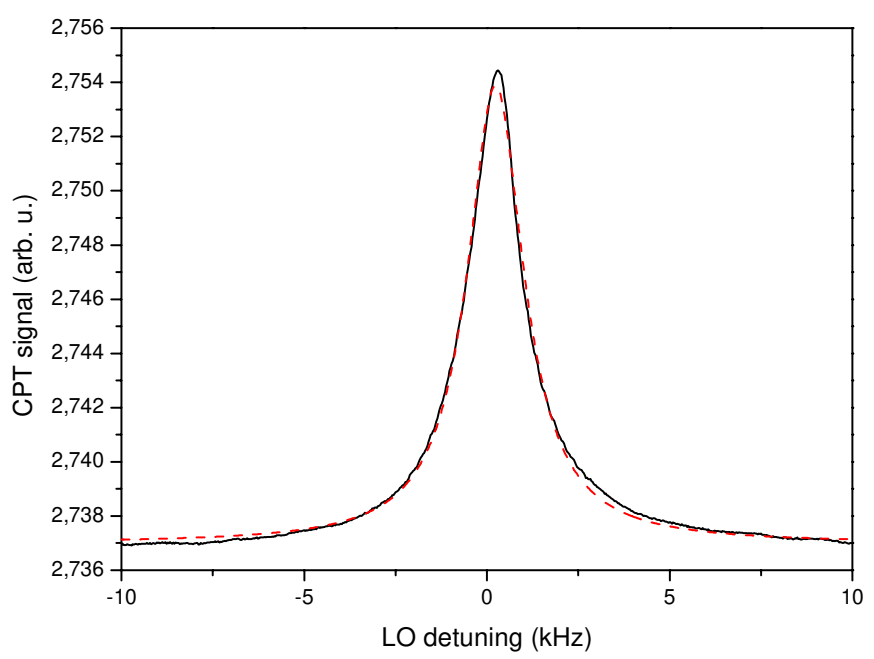

Figure 4. Typical $1.8 \mathrm{kHz}$ linewidth CPT resonance detected in the A04 cell.

$1.76 \mathrm{kHz}$ ) and from batch $\mathrm{B}$ in the range $[1.59 \mathrm{kHz}-1.75 \mathrm{kHz}]$ (average: $1.66 \mathrm{kHz}$ ).

Figure 5 shows pressures in $\mathrm{Cs}-\mathrm{Ne}$ cells derived from the measured collisional frequency shift of the CPT resonance for the two considered batches. Except for one cell in each batch, the Ne pressure is found to be similar among the cells of a common batch. For cells Axx, the average pressure is 104.6 mbar. The minimum and maximum pressure is measured to be 103.3 and 108.2 mbar respectively. This corresponds to a pressure deviation of $4.5 \%$. The latter would be reduced to $2 \%$ if the cell A08 is removed from the study. For cells $\mathrm{Bxx}$, average pressure is 122.1 mbar whereas minimum and maximum pressures are 119.7 and 124.3 mbar respectively. This corresponds to a pressure deviation of $7.7 \%$. Once again, the latter would be reduced to $3.7 \%$ if the cell B02 is not considered. For the two batches, the average pressures are 28.4 and 10.9 mbar lower than the set pressure, respectively. The difference in Ne pressure between the two batches is around

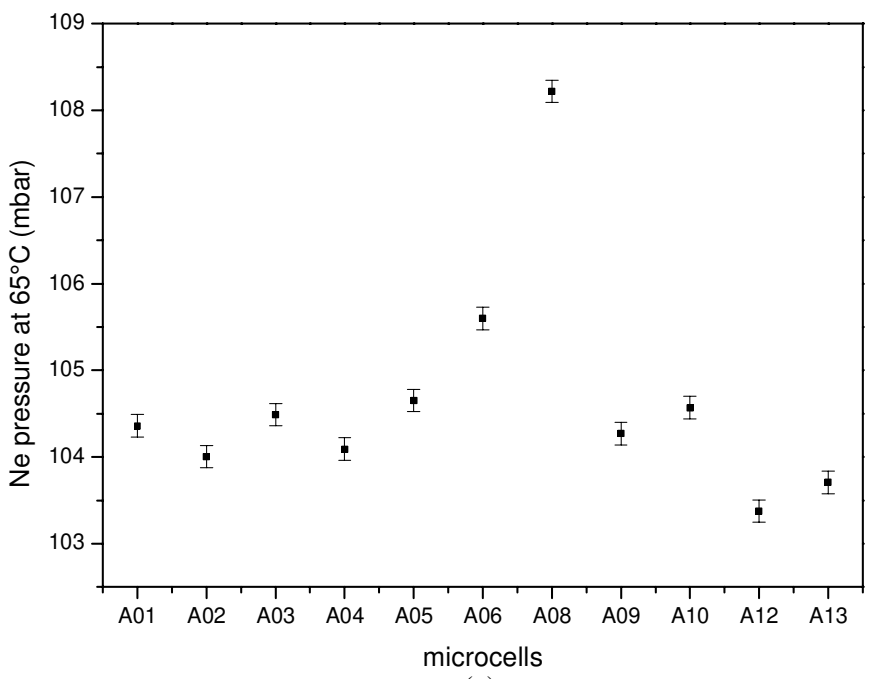

(a)
$15 \%$ and is considered to result from the uncertainty of our Ne filling system.

\subsection{Frequency stability measurements}

For further investigations, accelerated aging tests were performed in order to evaluate the variation of the cell inner atmosphere along time. The clock signal lineshape and frequency were first measured in $\mathrm{Cs}-\mathrm{Ne}$ cell at $80{ }^{\circ} \mathrm{C}$ cell temperature. Then, the cells were placed in an oven at $110{ }^{\circ} \mathrm{C}$ during 240 h, i.e. 10 days. Employing the so-called ' $\mathrm{Q}_{10}=$ 2 method' [23], it can be considered equivalent to an aging test of $24 \times 10 \times 8=1920 \mathrm{~h}$ at $80{ }^{\circ} \mathrm{C}$, i.e. nearly 2.6 months. The clock signal lineshape and frequency in the cell were then measured again at $80{ }^{\circ} \mathrm{C}$. In both measurement sessions, experimental parameters are kept identical. Figure 6 shows the evolution of the CPT resonance frequency as a function of the laser power for 3 different cells (A01, B03, B05) before and after aging. Experimental data are fitted by a linear function. Extrapolation to null laser power is performed to cancel the so-called frequency light shift and isolate the collisional frequency shift value.

Similar fit function results are obtained for cells B03 and B05 fabricated in the same batch. For the 3 cells, measured light shift slopes are found to be about 1 to $3 \mathrm{~Hz} / \mu \mathrm{W}$. The clock frequency variation at null laser power, during the aging test equivalent to $1920 \mathrm{~h}$ at $80^{\circ} \mathrm{C}$, is lower than 53,1 , and $35 \mathrm{~Hz}$ for cells A01, B03 and B05 respectively, with uncertainties in the range of $100 \mathrm{~Hz}$. This result demonstrates the excellent stability of the cell inner atmosphere. For comparison, a Cs vapor microcell-based miniature atomic clock characterized by relative frequency stability below $10^{-11}$ at $1 \mathrm{~h}$ integration time has its frequency varying less than $0.1 \mathrm{~Hz}$ at $1 \mathrm{~h}$, i.e. less than $192 \mathrm{~Hz}$ in $1920 \mathrm{~h}$. The tested cells are below this limit. However, in order to further validate getter-cells, their compatibility to be used in a miniature atomic clock exhibiting a relative frequency stability of $10^{-11}$ at 1 day integration should be demonstrated. This will be analyzed in a near future by optimizing the frequency resolution of our setup or

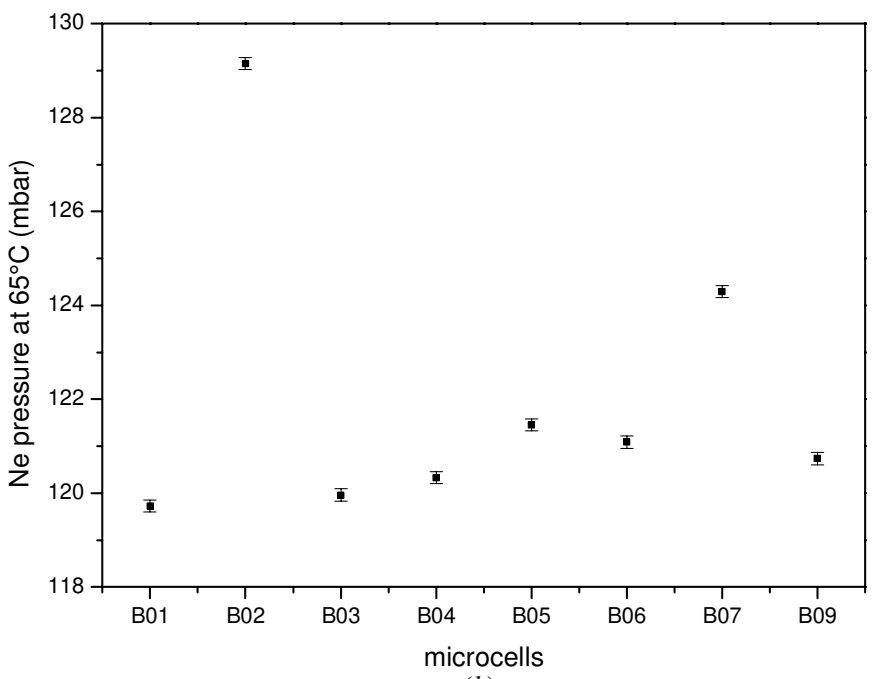

(b)

Figure 5. Estimated pressure at $65^{\circ} \mathrm{C}$ of the (a) Axx and (b) Bxx Cs-Ne cells using CPT resonance frequency measurements. 


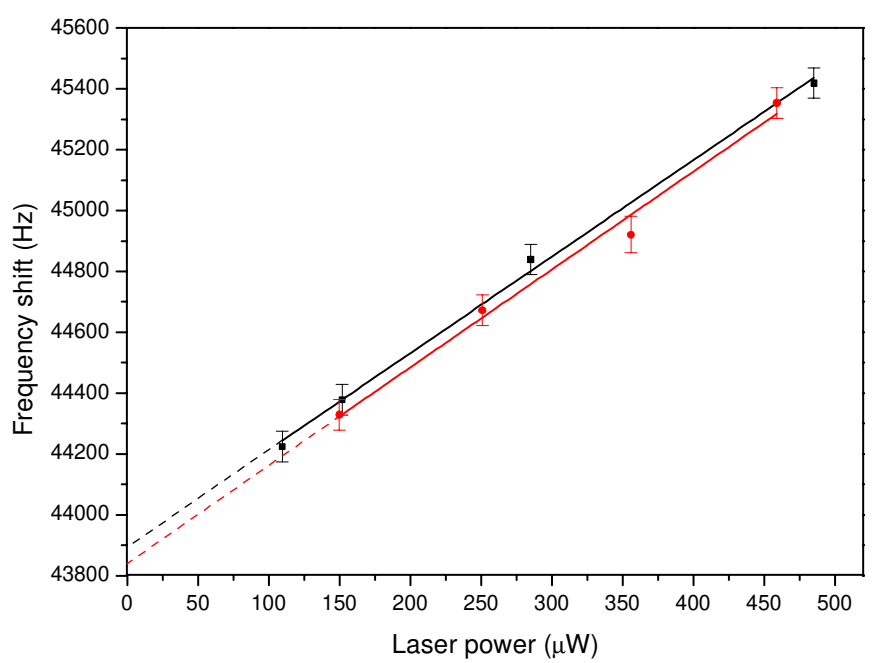

(a)

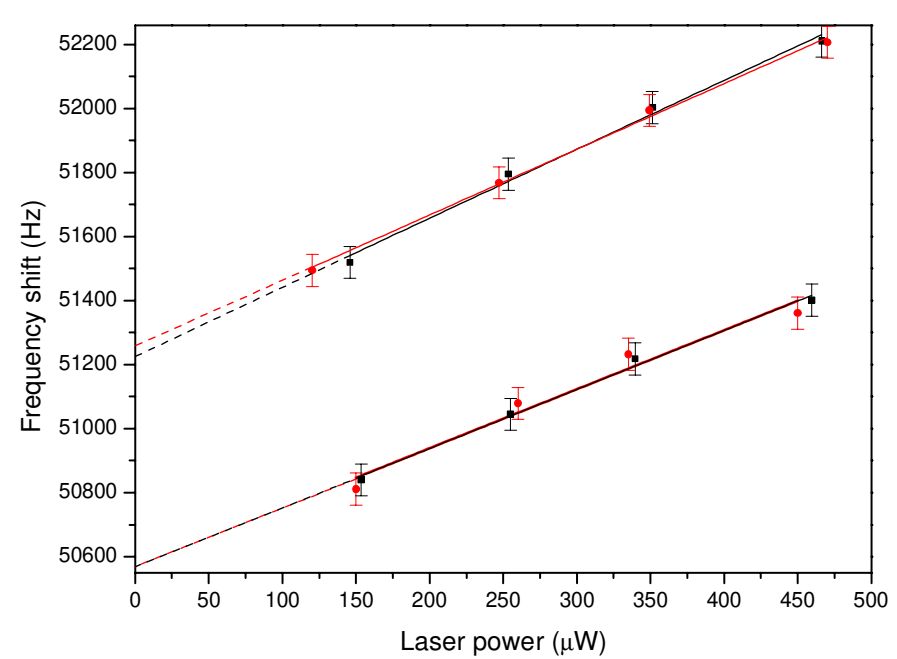

(b)

Figure 6. CPT resonance frequency measurements as a function of laser power of three different cells: (a) A01, (b) B03 (lower curve) and B05 (upper curve) before aging (black squares) and after aging (red circles). Experimental data are fitted by a linear function for extrapolation at null power.

increasing the time duration of the aging test. Such tests will be led in a growing number of cells to check the repeatability of performances of our cells.

\section{Conclusions}

The PageWafer ${ }^{\circledR}$ integration technology in miniature Cs-Ne cells for micro atomic clocks was investigated. The residual gas analysis with quadruple mass spectroscopy revealed that PageWafer ${ }^{\circledR}$ efficiently eliminates undesirable anodicbonding-related gases such as $\mathrm{H}_{2}, \mathrm{O}_{2}, \mathrm{~N}_{2}$ and $\mathrm{CO}_{2}$. Such cells achieve the impurity pressure in the order of $10^{-2}$ mbar which is $2 \%$ of that of the getter-free cells. CPT spectroscopy of the getter-integrated $\mathrm{Cs}-\mathrm{Ne}$ cells showed that Ne pressure is almost identical among the cells fabricated in one run (less than $5 \%$ deviation). We performed preliminary aging tests showing that these cells are compatible with the development of miniature atomic clocks exhibiting a relative frequency stability better than $10^{-11}$ at $1 \mathrm{~h}$ integration. Further tests are required to fully validate getter-cells on longer term.

\section{Acknowledgment}

This research was carried as a part of MAC-TFC project (EU FP7, grant no 224132) and thanks to Agence Nationale de la Recherche (ANR ISIMAC project, ANR-11-ASTR-004) and Délégation Générale de l'Armement (DGA).

\section{References}

[1] Liew L A, Knappe S, Moreland J, Robinson H, Hollberg L and Kitching J 2004 Microfabricated alkali atom vapor cells Appl. Phys. Lett. 84 2694-6

[2] Knappe S, Robinson H and Hollberg L 2007 Microfabricated saturated absoption laser spectrometer Opt. Express 15 6293-9
[3] Clark Griffith W, Knappe S and Kitching J 2010 Femtotesla atomic magnetometry in a microfabricated vapor cell $O p t$. Express 18 27167-72

[4] Lutwak R, Vlitas P, Varghese M, Mescher M, Serkland D K and Peake G M 2005 The MAC - a miniature atomic clock Proc. of 2005 Joint IEEE Int. Frequency Control (UFFC) Symp. and the 37th Annual Precise Time and Time Interval (PTTI) Systems and Applications Meeting (Vancouver, Canada, 2005) ed D Coler pp 752-7

[5] Knappe S, Gerginov V, Schwindt P D D, Shah V, Robinson H, Hollberg L and Kitching J 2005 Atomic vapor cells for chipscale atomic clocks with improved long-term frequency stability Opt. Lett. 30 2351-3

[6] Radhakrishnan S and Lal A 2005 Alkali metal-wax micropackets for chip-scale atomic clocks Dig. Tech. Pap.-Int. Conf. Solid State Sensors and Actuators and Microsystems, Transducers '05, (Seoul, Korea) vol 1 pp 23-6

[7] Liew L, Moreland J and Gerginov V 2006 Wafer-level fabrication and filling of cesium vapor cells for chip-scale atomic devices Proc. 20th Conf. Eurosensors (Göteborg, Sweden) W1B-P2

[8] Gong F, Jau Y Y, Jensen K and Happer W 2006 Electrolytic fabrication of atomic clock cells Rev. Sci. Instrum. 7776101

[9] Erklund E J, Shkel A M, Knappe S, Donley E and Kitching J 2008 Glass-blowing spherical microcells for chip-scale atomic devices Sensors Actuators A 143 175-80

[10] Mack S, Baumann H, Gösele U, Werner H and Schlögl R 1997 Analysis of bonding-related gas enclosure in micromachined cavities sealed by silicon wafer bonding J. Electrochem. Soc. 144 1106-11

[11] Farkas D M, Hudek K M, Salim E A, Segal S R, Squires M B and Anderson D Z 2010 A compact, transportable, microchip-based system for high repetition rate production of Bose-Einstein condensates Appl. Phys. Lett. 96093102

[12] Choa S-H 2005 Reliability of MEMS packaging: vacuum maintenance and packaging induced stress Microsyst. Technol. 11 1187-96

[13] Miletic D, Dziuban P, Boudot R, Hasegawa M, Chutani R K, Mileti G, Giordano V and Gorecki C 2010 Quadratic dependence on temperature of Cs 0-0 hyperfine resonance frequency in single Ne buffer gas microfabricated vapour cell Electron Lett. 4615 
[14] Nieradko L, Gorecki C, Douahi A, Giordano V and Beugnot J-C 2008 New approach of fabrication and dispensing of micromachined cesium vapor cell J. Micro/Nanolithography, MEMS, and MOEMS 7033013

[15] Hasegawa M, Chutani R K, Gorecki C, Boudot R, Dziuban P, Giordano V, Clatot S and Mauri L 2011 Microfabrication of cesium vapor cells with buffer gas for MEMS atomic clocks Sensors Actuators A 167 594-601

[16] Boudot R, Dziuban P, Hasegawa M, Chutani R K, Galliou S, Giordano V and Gorecki C 2011 Coherent population trapping resonances in $\mathrm{Cs}-\mathrm{Ne}$ vapor microcells for miniature clocks applications J. Appl. Phys. 109014912

[17] Boudot R, Liu X, Abbé P, Chutani R K, Passilly N, Galliou S, Gorecki C and Giordano V 2012 A high-performance frequency stability compact CPT clock based on a Cs-Ne microcell IEEE Trans. Ultrason. Ferroelectr. Freq. Control 59 2584-7
[18] SAES, PageWafer specs : http://www.saesgetters.com/ default.aspx?idPage $=1484$

[19] Boudot R, Miletic D, Dziuban P, Affolderbach C, Knapkiewicz P, Dziuban J, Mileti G, Giordano V and Gorecki C 2011 First-order cancellation of the Cs clock frequency temperature-dependence in $\mathrm{Ne}-\mathrm{Ar}$ buffer gas mixture Opt. Express 19 3106-14

[20] Dicke R H 1953 The effect of collisions upon the Doppler width of spectral lines Phys. Rev. Lett. 89 472-75

[21] Vanier J and Audoin C 1989 The Quantum Physics of Atomic Frequency Standards vol 1 (Bristol: IOP Publishing)

[22] Kozlova O, Guérandel S and De Clercq E 2011 Temperature and pressure shift of the Cs clock transition in the presence of buffer gases: Ne, N2, Ar Phys. Rev. A 83062714

[23] Lambert B J and Tang F W 2000 Rationale for practical medical device accelerated aging programs in AAMI TIR 17 Radiat. Phys. Chem. 57 349-53 